\title{
The presence of the proteolysis-inducing factor in urine does not predict the malignancy of a pancreatic tumour Niels Teich*1, Jörg Kleeff ${ }^{2}$, Herbert Lochs ${ }^{3}$, Joachim Mössner1 ${ }^{1}$, Volker Keim¹, Helmut Friess ${ }^{2}$ and Johann Ockenga ${ }^{3}$
}

\author{
Address: ${ }^{1}$ Universität Leipzig, Medizinische Klinik und Poliklinik II, Leipzig, Germany, ${ }^{2}$ Universität Heidelberg, Chirurgische Universitätsklinik, \\ Heidelberg, Germany and ${ }^{3}$ Charité Berlin, Medizinische Klinik und Poliklinik, Gastroenterologie, Hepatologie und Endokrinologie, Berlin, \\ Germany \\ Email: Niels Teich* - niels.teich@medizin.uni-leipzig.de; Jörg Kleeff - joerg_kleeff@med.uni-heidelberg.de; \\ Herbert Lochs - herbert.lochs@charite.de; Joachim Mössner - moej@medizin.uni-leipzig.de; Volker Keim - keimv@medizin.uni-leipzig.de; \\ Helmut Friess - helmut_friess@med.uni-heidelberg.de; Johann Ockenga - johann.ockenga@charite.de \\ * Corresponding author
}

Published: 21 June 2005

BMC Gastroenterology 2005, 5:20 doi:10.1186/I47|-230X-5-20
Received: 10 February 2005

Accepted: 21 June 2005

This article is available from: http://www.biomedcentral.com/l47I-230X/5/20

(c) 2005 Teichs et al; licensee BioMed Central Ltd.

This is an Open Access article distributed under the terms of the Creative Commons Attribution License (http://creativecommons.org/licenses/by/2.0), which permits unrestricted use, distribution, and reproduction in any medium, provided the original work is properly cited.

\begin{abstract}
Background: The proteolysis-inducing factor (PIF) was identified as a tumour product in various gastrointestinal cancers. A previous study in pancreatic cancer patients suggested PIF expression as a tumour marker, which is not related to tumour size. We hypothesized that PIF could be a useful marker to exclude benign pancreatic tumors, as chronic pancreatitis with a pancreatic mass.

Methods: Urine of patients with a pancreatic mass of uncertain malignancy was investigated for PIF expression by Western blot. Sufficient urine protein for analysis was available in 59 patients. The diagnosis was established by histology in 54 patients and by follow up in five patients with chronic pancreatitis. In addition, serum CAI9-9 was measured.

Results: The sensitivity (specifity) for the detection of a malignant pancreatic tumour was $90 \%$ (75\%) and 54\% (7I\%) for CA 19-9 and PIF, respectively. The sensitivity (specifity) for the distinction of pancreatic cancer from chronic pancreatitis was $89 \%$ (80\%) and 57\% (63\%) for CAI9-9 and PIF, respectively.
\end{abstract}

Conclusion: Evaluation of PIF in urine is of no diagnostic value in patients with a pancreatic mass of unknown malignancy.

\section{Background}

Distinction between benign and malignant pancreatic tumours is still difficult, despite significant progress in imaging techniques. Patients with chronic pancreatitis are at increased risk to develop pancreatic cancer [1]. Pancreatic inflammation, as observed in chronic pancreatitis, can be mistaken on imaging as cancer and inversely. Serum carbohydrate antigen 19-9 (CA19-9) levels are ele- vated in $80 \%$ of pancreatic cancer patients, but can also be increased in $20 \%$ of patients with chronic pancreatitis [2]. An accurate and non-invasive test to differentiate pancreatic cancer from chronic pancreatitis is not available.

Cancer frequently induces cachexia, but not all cancer patients will develop cachexia. This is not necessarily a late phenomenon in tumour progression. It may be 
present at diagnosis and may be the leading symptom that induces search for a tumour. A study of pancreatic cancer patients revealed that patients had lost a median of about $14 \%$ of their usual body weight at the time of diagnosis, and that this weight loss was progressive, increasing to a median of $25 \%$ at the time of the last assessment [3]. The central role in this process of - predominant - skeletal muscle waste seems to play the proteolysis-inducing factor (PIF) [4].

PIF is a $24-\mathrm{kDa}$ sulphated glycoprotein synthesized by cachexia-inducing murine and human tumours, which induces catabolism of myofibrillar proteins in skeletal muscle via a direct stimulation of the proteasome pathway in muscle cells [5]. Administration of PIF to normal mice leads to a rapid decrease in body weight, which is based primarily on a loss of skeletal muscle mass $[4,6]$.

PIF is expressed in a variety of gastrointestinal cancers [7]. It was detected in the urine of 44 from 55 pancreatic cancer patients, who had a significantly greater total weight loss and rate of weight loss than patients whose urine did not contain PIF. Interestingly, PIF expression was not dependent on cancer stage, but seemed to be a qualitative marker of pancreatic cancer: even stage 2 tumours expressed PIF in 83 per cent [8].

PIF has not been investigated in benign pancreatic diseases. We therefore hypothesized that PIF production in patients with a pancreatic tumour would clearly indicate the malignant nature of the disease. Special attention was paid to a clear distinction to a pancreatic mass caused by chronic pancreatitis.

\section{Methods}

100 patients with a pancreatic mass of uncertain malignancy (detected by computed tomography, magnet resonance tomography, ultrasound and/or endoscopic retrograde cholangiopancreaticography) were investigated. Patients with UICC stage 4 (locally extended and metastasised disease) were not enrolled. After collection of urine from all study participants, we investigated $30 \mathrm{ml}$ urine for the presence of PIF with a specific mouse monoclonal antibody in a Western blot setting as described recently $[4,8]$. In brief, urine protein was precipitated with ammonium sulphate and dialysed against water between 12 and 15 hours (overnight) with a molecular weight cutoff of $10 \mathrm{kD}$ (Slide-A-Lyzer Dialysis Cassette). $5 \mu \mathrm{g}$ of concentrated samples were separated with sodium dodecylsulphate polyacrylamide gel electrophoresis and subsequently blotted on nitrocellulose membranes. After incubation with $10 \mu \mathrm{g} / \mathrm{ml}$ of the mouse monoclonal PIF antibody (provided with courtesy by MJ Tisdale) and streptavidine horseradish peroxidase conjugate, the bands were detected using the Fluorescent ECL Plus system
(Amersham). In addition, CA19-9 in serum was measured with an electrochemiluminescence immunoassay (CA19$9^{\oplus}$ Roche Diagnostics or ADVIA Centaur ${ }^{\circledast}$, Bayer Healthcare), the upper limit of normal was $22 \mathrm{U} / \mathrm{ml}$. The ethics committees of the three participating centres approved this protocol.

\section{Results and discussion}

The analysis failed in 41 patients due to insufficient amount of urinary protein after dialysis. In 59 patients, PIF Western blot was successfully performed (figure 1). This cohort was subsequently assessed: it included 31 male and 28 female patients (median age 59 years, range 33-89 years). The diagnoses of the patients were shown in figure 2. Final diagnosis was done by histology in 54 patients or follow up for at least one year in five patients with chronic pancreatitis, who did not undergo surgery.

The diagnostic values of PIF for the detection of a malignant pancreatic tumour and with special attention to pancreatic cancer are shown in table 1. Summarizing all 59 patients, the median CA19-9 values in patients with benign or malignant pancreatic tumours were 16.5 (standard deviation (SD): 141) and 477 (SD: $22173 \mathrm{U} / \mathrm{l}$ ), respectively $(\mathrm{p}<0.05)$. The median CA19-9 values in patients with chronic pancreatitis and pancreatic cancer were 15.0 (SD: 18) and 478.5 U/l (SD: 22022), respectively $(\mathrm{p}<0.05)$. The analysis of CA19-9 in dependence on the presence of PIF in urine in PIF negative patients revealed 22.5 U/l (SD: 742) and 580.5 U/l in PIF positive patients (SD: 25203) $(\mathrm{p}<0.05)$. PIF was detected in two patients with CA19-9 negative pancreatic cancer, but was not detectable in 16 pancreatic cancer patients (15 of them with elevated CA19-9).

This is the first attempt to evaluate the proteolysis-inducing factor as a diagnostic marker of pancreatic cancer in patients with a potentially resectable pancreatic tumour. We found a weak association with malignancy, but the diagnostic value to distinguish benign from malignant pancreatic tumours is lower than CA19-9. PIF seems to be of a rather limited importance to answer this question in every-day care.

A major drawback of our data is the high amount of patients with insufficient urinary protein after extraction and dialysis. For practical reasons in this multi-centre collaboration, we tried to investigate PIF in a small urine sample, as initially suggested by Todorov et al. [4]. Our problem could be potentially solved by the collection of higher urine volumes in further studies.

PIF was detected in 6 patients with chronic pancreatitis without evidence for a malignancy by 12 months follow up or histology. This raises the question about the origin 


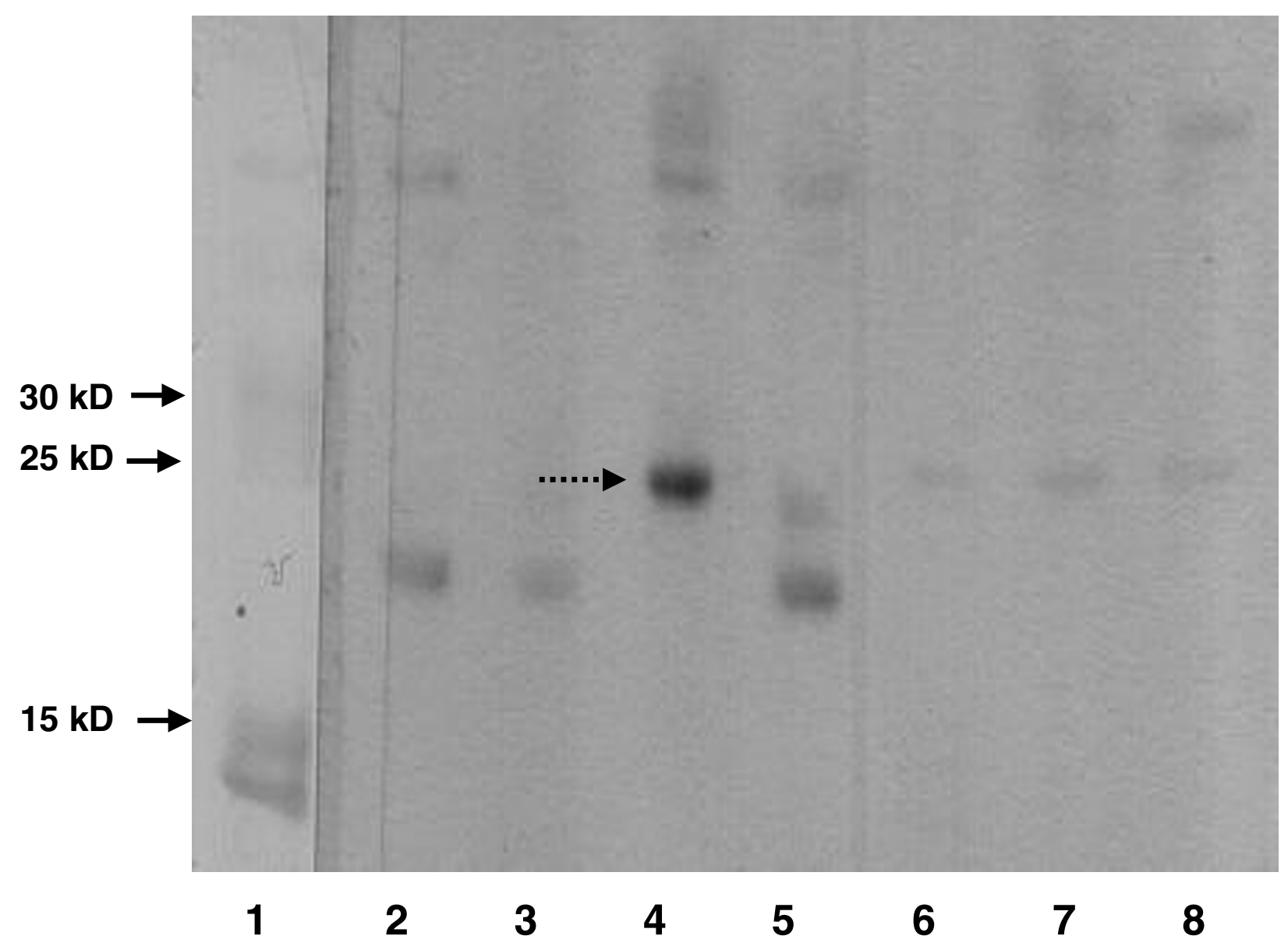

\section{Figure I}

Western blot analysis for PIF after urinary protein extraction. Lane I: Rainbow ${ }^{\circledR}$ recombinant protein molecular weight marker (\#RPN 800, Amersham Life Science); lane 2: healthy control person, lanes 3 and 5: chronic pancreatitis, PIF not detected, lanes 4 and 7: pancreatic cancer, UICC stage I and 2, respectively, PIF detected (24 kD, broken line); lanes 6: chronic pancreatitis, PIF detected; lane 8: positive control (pancreatic cancer, UICC stage 4)

of PIF in these patients. Although the majority of investigations found PIF expression only in tumour tissue, the expression of PIF in non-malignant tissue has been also reported [7]. The primary role of PIF seems to be in regulation of development [9]. After cloning of the cDNA for PIF, a human homologue - the human cachexia associated protein (HCAP) - has been identified, which is minimally expressed in normal tissues $[10,11]$. It can be speculated, that the ongoing inflammation in patients with chronic pancreatitis is capable to generate PIF. This could explain the low specifity of PIF to detect pancreatic malignancies in our study. Three patients with pancreatic cancer had normal CA19-9 values, two of them were PIFpositive. A sequential testing of PIF in the case of a CA199-negative pancreatic tumour may be beneficial but has to be considered cautiously based on these small patient numbers. However, even this approach would fail to detect all pancreatic cancer patients in our study.

Although our data indicate that PIF is not helpful as a diagnostic marker of pancreatic cancer, a benefit may be the early identification of patients who need nutritional intervention [12]. In previous studies the detection of PIF was associated with prior weight loss. PIF induces an increase of the ubiquitin - proteasome activity resulting in protein catabolism. Administration of the polyunsaturated fatty acid eicosapentaenoic acid (EPA) attenuates protein degradation by antagonizing the PIF induced up regulation of the ubiquitin - proteasome proteolytic pathway in cachectic tumour bearing mice [13]. A first 


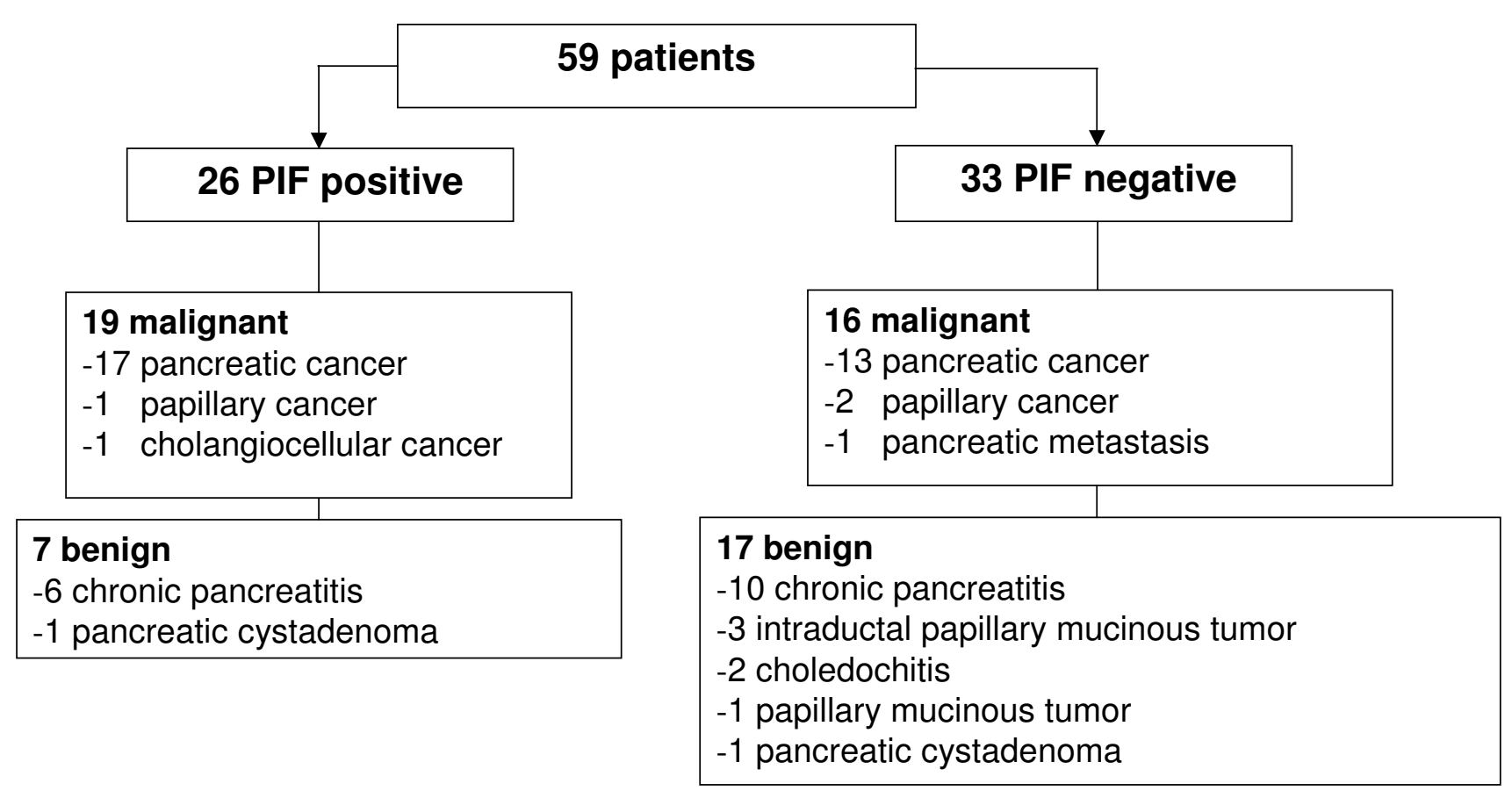

Figure 2

Diagnoses in PIF positive and PIF negative patients

Table I: Diagnostic values of PIF in comparison to CAI9-9 to discriminate malignant vs. benign and pancreatic cancer (PaCa) vs. chronic pancreatitis (CP).

\begin{tabular}{|c|c|c|c|c|}
\hline & \multicolumn{2}{|c|}{ all malignant vs. all benign } & \multicolumn{2}{|c|}{ PaCa vs. CP } \\
\hline & PIF & CA19-9 & PIF & CAI9-9 \\
\hline Sensitivity & $54 \%$ & $90 \%$ & $57 \%$ & $89 \%$ \\
\hline Specifity & $71 \%$ & $75 \%$ & $63 \%$ & $80 \%$ \\
\hline $\begin{array}{l}\text { positive predictive } \\
\text { value }\end{array}$ & $73 \%$ & $88 \%$ & $74 \%$ & $93 \%$ \\
\hline $\begin{array}{l}\text { negative predictive } \\
\text { value }\end{array}$ & $52 \%$ & $80 \%$ & $44 \%$ & $73 \%$ \\
\hline
\end{tabular}

randomised placebo - controlled trial in patients with pancreatic cancer suggest that a EPA enriched oral supplement has the potential to induce a net gain of weight, lean body mass and improvement of quality of life [14].

\section{Conclusion}

PIF is not superior to the established tumour marker CA19-9 to distinguish benign from malignant pancreatic tumours. Further investigations should clarify whether the onset of PIF expression in the long-term follow-up of chronic pancreatitis patients is associated with early malignancy and whether it precedes morphologic and clinical signs of pancreatic cancer. In future, the evaluation of PIF as an indicator for early nutritional intervention seems to be warranted.

\section{Abbreviations}

proteolysis-inducing factor PIF 
pancreatic cancer $\mathrm{PaCa}$

chronic pancreatitis CP

carbohydrate antigen 19-9 CA19-9

eicosapentaenoic acid EPA

standard deviation SD

\section{Competing interests}

The author(s) declare that they have no competing interests.

\section{Authors' contributions}

N.T and J.O. had the initial idea and initiated the study. N.T. co-ordinated the laboratory analysis. All authors ascertained patients in this multicenter investigation, wrote and discussed the final manuscript.

\section{Acknowledgements}

We thank Professor M.J. Tisdale for kindly providing the anti-PIF-antibody. We furthermore thank S. Kistner and T. Herrmann for expert technical assistance.

\section{References}

I. Malka D, Hammel P, Maire F, Rufat P, Madeira I, Pessione F, Levy P, Ruszniewski P: Risk of pancreatic adenocarcinoma in chronic pancreatitis. Gut 2002, 5 I:849-52.

2. Satake K, Takeuchi T: Comparison of CAI9-9 with other tumor markers in the diagnosis of cancer of the pancreas. Pancreas 1994, 9:720-724.

3. Wigmore SJ, Plester CE, Richardson RA, Fearon $\mathrm{KCH}$ : Changes in nutritional status associated with unresectable pancreatic cancer. Br J Cancer 1997, 75: 106-109.

4. Todorov P, Cariuk P, McDevitt T, Coles B, Fearon K, Tisdale M: Characterization of a cancer cachectic factor. Nature 1996, 379:739-42

5. Lorite MJ, Smith HJ, Arnold JA, Morris A, Thompson MG, Tisdale MJ: Activation of ATP-ubiquitin-dependent proteolysis in skeletal muscle in vivo and murine myoblasts in vitro by a proteolysis-inducing factor (PIF). Br J Cancer 200I, 85:297-302.

6. Tisdale MJ: The 'cancer cachectic factor'. Support Care Cancer 2003, II:73-78.

7. Cabal-Manzano R, Bhargava P, Torres-Duarte A, Marshall J, Bhargava $\mathrm{P}$, Wainer IW: Proteolysis-inducing factor is expressed in tumours of patients with gastrointestinal cancers and correlates with weight loss. Br J Cancer 200I, 84:1599-I60I.

8. Wigmore SJ, Todorov PT, Barber MD, Ross JA, Tisdale MJ, Fearon $\mathrm{KCH}$ : Characteristics of patients with pancreatic cancer expressing a novel cancer cachectic factor. Br J Surg 2000, 87:53-58.

9. Caruik P, Lorite MJ, Todorov PT, Field WN, Wigmore SJ, Tisdale MJ: Induction of cachexia in mice by a product isolated from the urine of cachectic cancer patients. BrJ Cancer 1997, 76:606-6I3.

10. Schittek B, Hipfel R, Sauer B, Bauer J, Kalbacher H, Stevanovic S, Schirle M, Schroeder K, Blin N, Meier F, Rassner G, Garbe C: Dermcidin: a novel antibiotic peptide secreted by sweat glands. Nat Immunol 2001, 2: I I33-1 I37.

II. Porter D, Weremowicz S, Chin K, Seth P, Keshaviah A, Lahti-Domenici J, Bae YK, Monitto CL, Merlos-Suarez A, Chan J, Hulette CM, Richardson A, Morton CC, Marks J, Duyao M, Hruban R, Gabrielson E, Gelman R, Polyak K: A neural survival factor is a candidate oncogene in breast cancer. Proc Natl Acad Sci USA 2003, 100:10931-10936
12. Ockenga J, Pirlich M, Gastell S, Lochs H: Tumoranorexie Tumorkachexie in der Gastroenterologie: Standards und Visionen. Z Gastroenterol 2002, 40:929-936.

13. Whitehouse AS, Smith HJ, Drake JL, Tisdale MJ: Mechanism of attenuation of skeletal muscle protein catabolism in cancer cachexia by eicosapentaenoic acid. Cancer Res 200I, 61:3604-3609.

14. Fearon KC, von Meyenfeldt MF, Moses AG, van Geenen R, Roy A, Gouma DJ, Giacosa A, van Gossum A, Bauer J, Barber MD, Aaronson $\mathrm{NK}$, Voss $A C$, Tisdale MJ: Effect of a protein and energy dense N-3 fatty acid enriched oral supplement on loss of weight and lean tissue in cancer cachexia: a randomised double blind trial. Gut 2003, 52:1479-1486.

\section{Pre-publication history}

The pre-publication history for this paper can be accessed here:

http://www.biomedcentral.com/1471-230X/5/20/pre pub
Publish with Biomed Central and every scientist can read your work free of charge

"BioMed Central will be the most significant development for disseminating the results of biomedical research in our lifetime. "

Sir Paul Nurse, Cancer Research UK

Your research papers will be:

- available free of charge to the entire biomedical community

- peer reviewed and published immediately upon acceptance

- cited in PubMed and archived on PubMed Central

- yours - you keep the copyright
BioMedcentral 